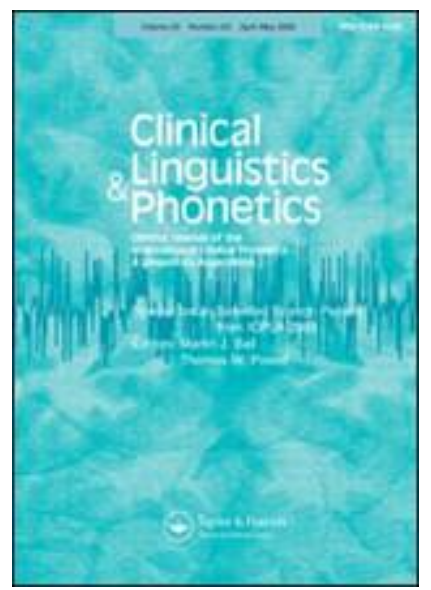

\title{
To initiate repair or not? Coping with difficulties in the talk of adults with intellectual disabilities.
}

\begin{tabular}{|r|l|}
\hline Journal: & Clinical Linguistics \& Phonetics \\
\hline Manuscript ID & TCLP-2019-0098.R1 \\
\hline Manuscript Type: & Original paper \\
\hline Keywords: & $\begin{array}{l}\text { talk, repair, conversation analysis }<\text { language measurement }<\text { language, } \\
\text { intellectual disability }\end{array}$ \\
\hline \multicolumn{2}{|l}{} \\
\end{tabular}

\section{SCHOLARONE \\ Manuscripts}




\begin{abstract}
How do health and social care professionals deal with undecipherable talk produced by adults with intellectual disabilities (ID)? Some of their practices are familiar from the other-initiated repair canon. But some practices seem designed for, or at least responsive to, the needs of the institutional task at hand, rather than those of difficult-to-understand conversational partners. One such practice is to reduce the likelihood of the person with ID issuing any but the least repair-likely utterances, or indeed having to speak at all. If they do produce a repairable turn, then, as foreshadowed by Barnes and Ferguson's (2015) work on conversations with people with aphasia, their interlocutors may overlook its deficiencies, respond only minimally, simply pass up taking a turn, or deal with it discreetly with an embedded repair. When the interlocutor does call for a repair, they will tend to offer candidate understandings built from comparatively flimsy evidence in the ID speaker's utterance. Open-class repair initiators are reserved for utterances with the least evidence to go on, and the greatest projection of a response from the interlocutor. We reflect on what this tells us about the dilemma facing those who support people with intellectual disabilities.
\end{abstract}

\title{
$\underline{\text { Introduction }}$
}

People with developmental intellectual disabilities (for example, Down syndrome, autism) can experience a range of communicative difficulties, depending on the severity of their condition. Traditional means of researching their communication tends to be a matter of competence-testing based on question-and-answer tests, or, at a still further remove from the actuality of what happens in their lives, on third-party reports from teachers, support staff, family, and so on. Research based on recordings of what they do in everyday circumstances, unmediated by test conditions, is still in the minority. But Yearley and Brewer (1989) began, with a study of people with Down syndrome, to show competences that were hitherto unsuspected, and the close focus on actual talk in that study has proved useful ever since in identifying what happens in interactions involving people with a wide range of communicative impairments (for an overview, see Antaki and Wilkinson, 2012). One signal discovery to come out of that work (heavily influenced by the pioneering work of Charles Goodwin, on aphasia - see, for example, Goodwin, 1995, and the collection in Goodwin, 2003 ) is the detailed analysis of the crucial role played by the interlocutor. The accumulated evidence confirms that it would be misleading to try to get the measure of the communicative implications of living with intellectual disabilities without including their interlocutor in the picture .

What the interlocutor does will, or ought, help bring out the person with disability's competences. But with such an asymmetry in their cognitive abilities, and probably their authority, what the interlocutor does is likely to shape the meaning of the talk of the person with the disability, and perhaps channel into what they consider to be more appropriate 
directions. One way of shaping and channelling a speaker's next turn is to query the last one; and that, in its various forms, is what other-initiated repair does (Kitzinger, 2012).

But unintelligible talk is not always picked out for repair by an interlocutor.

Conversationalists will be alive to the delicacy of finding fault with another's talk, and in casual conversation between peers, the overwhelming preference is for self-repair (see Kendrick 2015 for a picture of the statistical distribution of repairs in English). This delicacy about (putting it strongly) correcting others will be tested more frequently, as Wilkinson argues, in cases like aphasia, where one of the speakers is especially unclear (Wilkinson, 1995). Indeed, early reports by Perkins $(1995,2003)$ show when the person with aphasia is a family member, in at least some cases conversationalists will ignore their disfluencies, even at the expense of letting meaning slip, rather than risk seeming to, as Perkins puts it, attribute faulty talk to "personal insufficiency" and make a consequent "threat to face" (2003, p 159).

Barnes \& Ferguson (2015) take up Perkin's observation and systematically go through the ways in which a conversationalist handles an aphasic partner's turns without resorting to other-initiated repair (asking what?, and so on). The three alternatives they find partners using are "receipting responses, accounting responses, and "other" responses. .." (2015, p 315). Receipting responses register that the person with aphasia has produced a turn, but do little more - most crucially, they "provide little support for the action implemented by the turn" as the authors put it. Among other ways of dealing with it, they pick out 'accounting" by which they mean something like calling attention to the problem in the turn of the speaker with aphasia, but effectively dismissing it (as in one of their examples: none of that made sense, did it?). All of these manage not to engage substantively with what they were trying to say (or more importantly, what they were trying to do by saying it). As Barnes and Ferguson point out, (echoing Perkins' warning from her 2003 chapter), "restricting their ability to implement social action, and making relevant their status as linguistically incompetent" (2015, p 315) .

Service providers and service-users.

The findings referred to above came from studies of everyday conversationalists and their family members. Would one expect any different when the speakers are service-providers and intellectually impaired service-users? Laakso (2003) compares cases where a man with aphasia is in conversation with his wife and with a clinician; it is the clinician who intervenes less - and "this may be due to an institutional practice, as the interlocutor is a speech and language therapist" (2003 p 181). That is reasonable: at some point, the clinician must leave the client to make the mistakes that allows the clinician to make a full diagnosis.

Yet, outside the speech and language clinic, for staff who are not assessing the service user, other considerations would seem to be in play. One the one hand, support workers, occupational therapists and others have the professional mandate of helping the service user flourish and also expected to have an ideological commitment of promoting self-expression and self-determination of person with ID. That entails helping express themselves as fully as possible - including by other-initiated repair. But on the other hand, all such professionals are also under the obligation to bring whatever service they are offering to a conclusion (getting a training centre activity done, getting an instructional lesson completed) which might point in a different direction.

The question to be asked, then, is what happens when a practitioner, who may have institutional goals to achieve, deals with linguistically problematic and/or otherwise 
troublesome turns that they are likely to encounter in the talk of service-users with intellectual disabilities. Answering this question provides important information about the nature of the communicative environments encountered by people with intellectual disabilities, and the specific communicative implications of intellectual disability for everyday life.

\section{$\underline{\text { Data }}$}

The data we draw on in this article come from three kinds of institutional setting gardening activity centres (of which there are two: one, "Foxwood", designed simply for supervised activity, the other, "GardenSpace" for more systematic horticulture therapy); a supported residence ("Comber Hall"); and medical health-checks, either in neighbourhood primary care centres or their own homes. The service-users (or SUs, as we will occasionally refer to them for convenience) varied greatly in their communicative abilities (though no information was available to us as to their aetiologies). We have concentrated in this article on those who had at least some language capacity, and could both understand simple sentences and produce lexically-recognisable utterances. In all cases, ethical approval was provided by the relevant author's University, or from an NHS Research Ethics Committee, and written informed consent was received from all parties for the data to be used in the anonymised and pseudonymised form reported here.

The filming of the health-checks was fairly standardised, the video capturing the interaction between practitioner and patient (usually with a companion) from start to finish. The videos in the garden centres and the sheltered home were less standardised, shooting opportunistically to capture the run of everyday activities ${ }^{1}$.

\section{$\underline{\text { Analysis }}$}

It is important to note that in all these settings there is, apart from their different cognitive and communicative capacities, a clear official asymmetry between the intellectually-disabled service user and their interlocutor. The latter is always a professional person (or, in the case of the horticultural therapy centre, a volunteer working under the supervision of a professional) who has an institutional objective, and the authority to encourage the serviceuser to comply in its realisation. Not surprisingly, a great deal of the talk - the overwhelming volume of it - is task-relevant, initiated by the service-provider, and consisting mostly of sequences based on questions (usually 'test' questions) or instructions. Casual conversation was rare. So the kinds of repair we see may not be easily compared to repair practices elsewhere in this special issue, where the conversations take place between people who are talking together with no specific object in mind, or at least no officially-sanctioned one.

Given that background, it is perhaps not surprising that the balance of other-initiated repair is different from what might be expected among typical speakers. In what follows, we shall show that the service-providers (support workers, garden therapists, doctors and nurses) orient to the service-users' communicative difficulties in two ways. On the one hand, they might act to head off the SU having to speak (and risk unintelligibility, and trouble thereafter) at all. The staff's professional status - especially their authority (or "deontic status" Stevanovic and Peräklyä, 2012) - gives them rights to issue directives and assessments, which

\footnotetext{
${ }^{1}$ The filming at Foxwood was done by Charles Antaki and Emma Richardson; at GardenSpace by Charles Antaki and Joe Sempik; at Comber Hall by Chris Walton; and in the clinics by Deborah Chinn.
} 
want only compliance or acknowledgement, and makes it easy to shape the conversation. On the other hand, if the service-user does speak, the service-provider may pass up the opportunity to initiate repair; or, if they do issue a repair initiator, they may do so by attributing meaning when they can, building a candidate understanding from whatever evidence there is in the ID speaker's utterance, or what has gone before. We shall see that the most challenging form of other-initiators of repair, "open-class" OIRs such as what? and sorry? (Drew, 1997), are reserved for utterances with the least evidence to go on. We start with a description pf practices that allow the service-provider to minimise the risk of having to deal with a repairable at all.

$\underline{\text { Speak to people with ID in ways that require little or no verbal reply, }}$

Since the early days of Sacks, Schegloff and Jefferson's pioneering work (1978), conversation analysts have formalised our everyday intuition about the conduct of talk by casting it as a matter of progressivity. In other words, that talk proceeds on the basis of a contract between participants that they should work to ensure that each gives the other whatever support is wanted, at each turn, to allow the next turn to be planned and delivered. Unintelligible talk is a threat if person A's turn can't be deciphered, then person B is unsure to proceed, and progressivity is lost.

There are many ways to improve the chances that participants' utterances will be of such a kind as least to threaten progressivity; one might ensure adequate audibility, clear speakerselection, a topic on which all parties are familiar enough to contribute, and so on. The most all-encompassing is to set up a scene in which the utterances of at least one party need only reach a very low bar, or none, to qualify as an intelligible turn. One such sequence is the instruction, acted out by tutor and pupil, allowing the tutor to deliver turns as instructions or explanations, and to treat the pupil's corresponding turns as compliances or acknowledgements. Here are two examples.

Extract 1 Moira and the cooking pot GardenSpace 013209.00

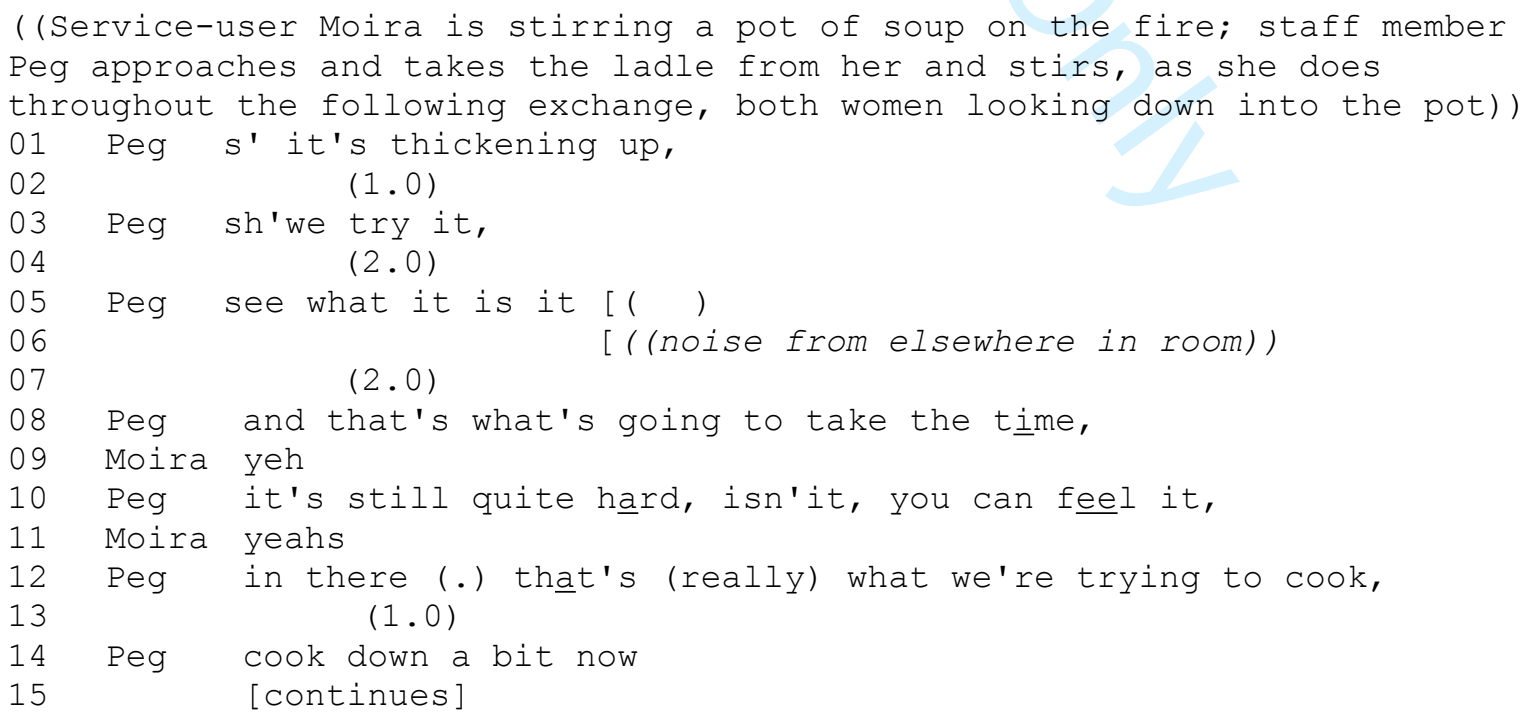




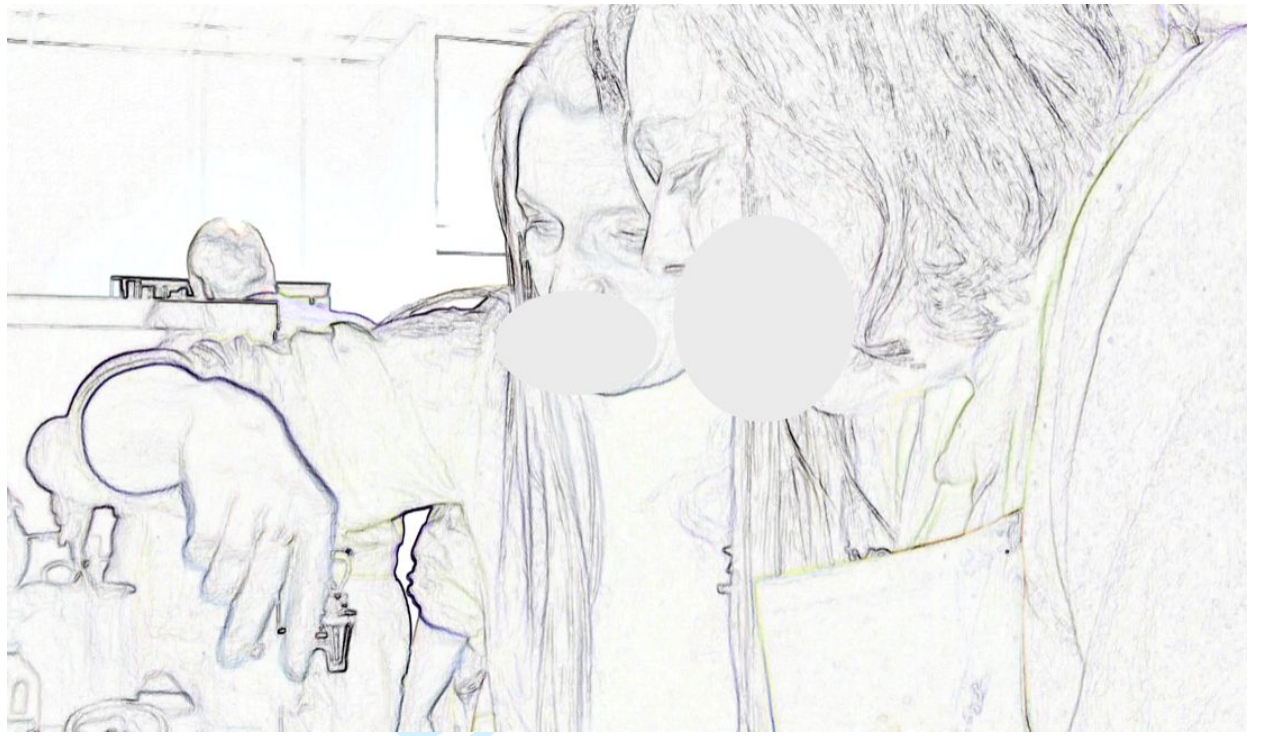

Figure 1. Peg (left) takes the ladle from Moira

In this scene, SU Moira has been tasked with stirring a pot of potato soup. Staff member Peg approaches and, with both she and Moira looking down at the pot, takes over the ladle and issues a series of assessments (it's thickening up, it's still quite hard and so on) which require, and receive, only minimal acknowledgment in a form that is very unlikely to cause any need for repair (yeh, yeahs). Even the instruction (line $3 s^{\prime}$ we try it) although ostensibly meant for both of them, requires nothing from Moira other than staying put and watching as Peg test the consistency of the potatoes in the soup. To be slightly more technical about it the low bar for Moira's responses is due to Peg's issuing these assessments from a position of greater authority, in virtue of her epistemic status as a experienced staff member, her epistemic stance as displayed by the unilateral format of the assessments, and her deontic status as the one who set Moira the task in the first place. In other words, Moira has neither need nor authority to produce anything very substantial, lowering the danger of Peg having to try and repair her words.

The case of service user Cameron and horticulture therapist Deborah, below, is more unusual, and more striking, but is an extension of the same principle.

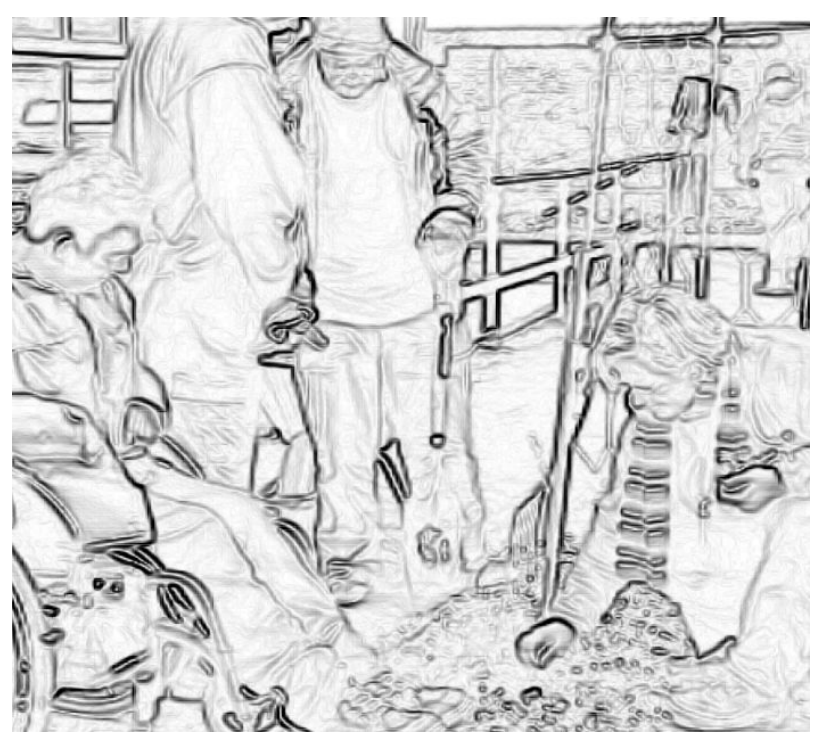

Figure 2. Cameron (left, in wheelchair) and Deb (at right, kneeling) 
Extract 2 GardenSpace Cameron and the plants

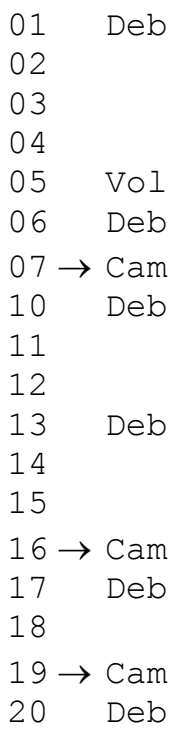

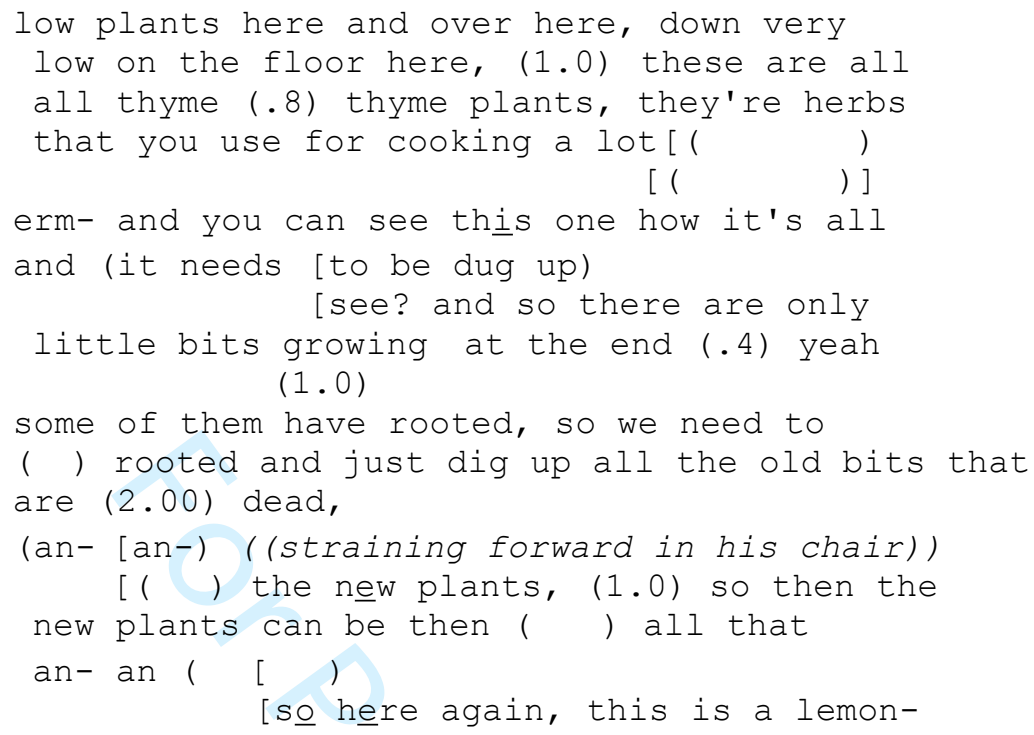

Deborah is describing the scene to a group of service-users, including Cameron (in the wheelchair in the image). Her turns are recognisably in the genre of exposition and explanation; it is a matter of her epistemic status licencing a steady series of turns requiring little or indeed no uptake from the assembled (by definition, less expert, or wholly inexpert) company. But there is a tear in the fabric at line 7, when Cameron issues a turn which syntactically and semantically provides a collaborative completion (Lerner, 1991) to what Deb is saying. Although seemingly well-formatted and sensible, it is wholly ignored; Deb continues speaking, leaving an ellipsis after see how this one is all in order to issue the more attention-orienting see? in the middle of, and therefore in competition with, Cameron's turn (it is not at or near the end of a turn-construction unit, and so not a transition-relevant point). Cameron has two more efforts (at lines 16 and 19), but each suffer the same fate. Where Peg in the earlier example had relied successfully on Moira producing only riskless minimal turns, here Deborah needed to take the extra step of actively ignoring Cameron to avoid the threat to progressivity that his talk might entail. The repair would not be of the word-search solution kind, but something like a challenge or a correction (eg., hypothetically: no, it doesn't need to be dug up), which would risk a marked threat to the progressivity of the interaction.

On the rare occasions on which the service-provider essayed a more conversational style, their deontic authority perforce became less relevant, but other contingencies could be brought into play to keep down the risk of the service-user producing talk that might interrupt progressivity. Here is an example.

Staff member Mickie is supervising service-user Douglas in filling a kettle from a large jerrycan. We see that Mickie begins with a risky wh- prefaced question (line 1-2), requiring a substantial response from Douglas. Whatever he says, and it is not easily decipherable on the video, but might be intelligible on-site to Mickie (who is used to Douglas's way of talking) is met with a general-purpose receipt in lines 6 and 8 . We shall have more to say about such receipts in a later section. Here we are concerned with what happens at lines 10 onwards.

Extract 3 Foxwood Garden Project 26.01.10 Daffodils 


\subsection{5}

((Douglas is bent down, filling a container from a jerrycan throughout this exchange))
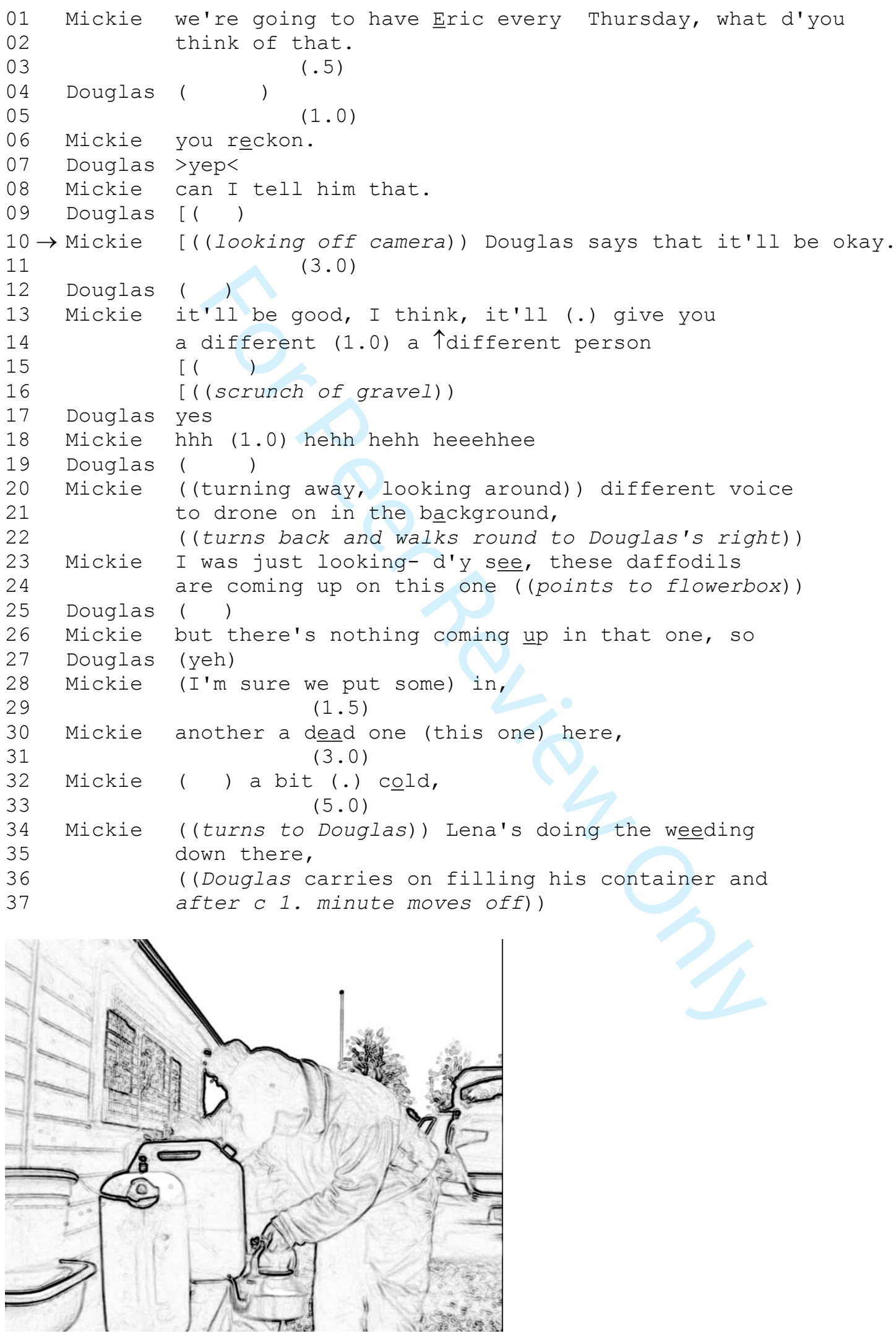
Figure 3. Mickie (looking down at a windowbox) and Douglas (filling a kettle), as from line 23

As from line 10, which is apparently designed for a listener off-screen, all Mickie's utterances allow for, but do not mandate, a response from Douglas. Indeed, Mickie designs her talk so as not to mobilise his response, as Stivers and Rossano (2010) would term it. On all the parameters which encourage or require a response (gaze, intonation, grammatical form, Kstatus) Mickie has chosen the weakest level. Thus, as Figure 3 shows, she is not in her recipient's eye line; neither the grammatical form of her utterances (declarative), nor their intonational contour (flat or downward) indicate a question to be answered; and the matter of which she speaks is better known to her than it is to her recipient (she is $\mathrm{K}+$ to his $\mathrm{K}$-, in Heritage and Raymond's 2005 terms). All these are anti-mobilisation, and both excuse Douglas from responding and Mickie from dealing with his utterance as a response if he makes one.

The above examples are cases where the interlocutor has designed their talk so as to minimise the projectability of a responsive utterance from the person with ID. This may of course be motivated by a number of factors, which are not mutually exclusive: to bring the conversation to a close, to avoid putting the person on the spot, and so on; but one thing it does do is excuse the recipient of having to take a turn that will, or may, require repair. In the next section we see what happens when such an utterance does in fact come.

Dealing with a repairable by not taking up the next-speaker slot at all

A turn at talk, unless it is some sequence-closing turn, usually requires uptake of one kind or another; to disattend it is dispreferred (though disattention can be done subtly; see Mandlebaum's classic work on disattending complaints, 1991) In the cases below, the person with ID has issued a turn that is less than fully intelligible., but, as Barnes and Ferguson (2015) put it, their interlocutor "passes over" a response - here, by simply disregarding the deficient utterance entirely.

One environment in which the interlocutor can pass on responding to that turn is where they are engaged in some visible activity that warrants their exclusive concentration. Examples 2 and 3 are cases of such environments, in the gardening setting.

Example 4 GardenSpace data 2011-12

00043-quicktime 02.45

Ruby squatting, engaged with plants; Harry standing, looking down

01 Ruby ((working silently on plants))

02 Harry (waja wja waja waja.)

$03 \rightarrow \quad$ (5.0) ((Ruby continues working))

04 Ruby ooh ((grunting with effort at pulling up plant))

[interaction continues]

Harry, the service user, is standing by while Ruby, the staff member, is squatting down by a flowerbed and working on the plants at floor level, body turned away from Harry. At line 2, Harry issues an utterance which may be a non-lexical vocalisation (although he can and does use lexical items on occasion). Rather than issue an OIR, - which would need probably to be of the open-class type - Ruby carries on working silently. 
The physical task gives the service-provider particular authority not to orient to a task-related repairable; but it provides the same opportunity even in stretches of talk that are (as in Example 4 above) more conversational, and not related to the task at hand. In the case below, Mickie is potting seeds while service users, Andrew and one other, are ostensibly following her example (in fact they are simply standing there). The talk has turned to shopping, and the benefits of having the goods delivered.

Example 5. Foxwood.

Seed sowing 08.40

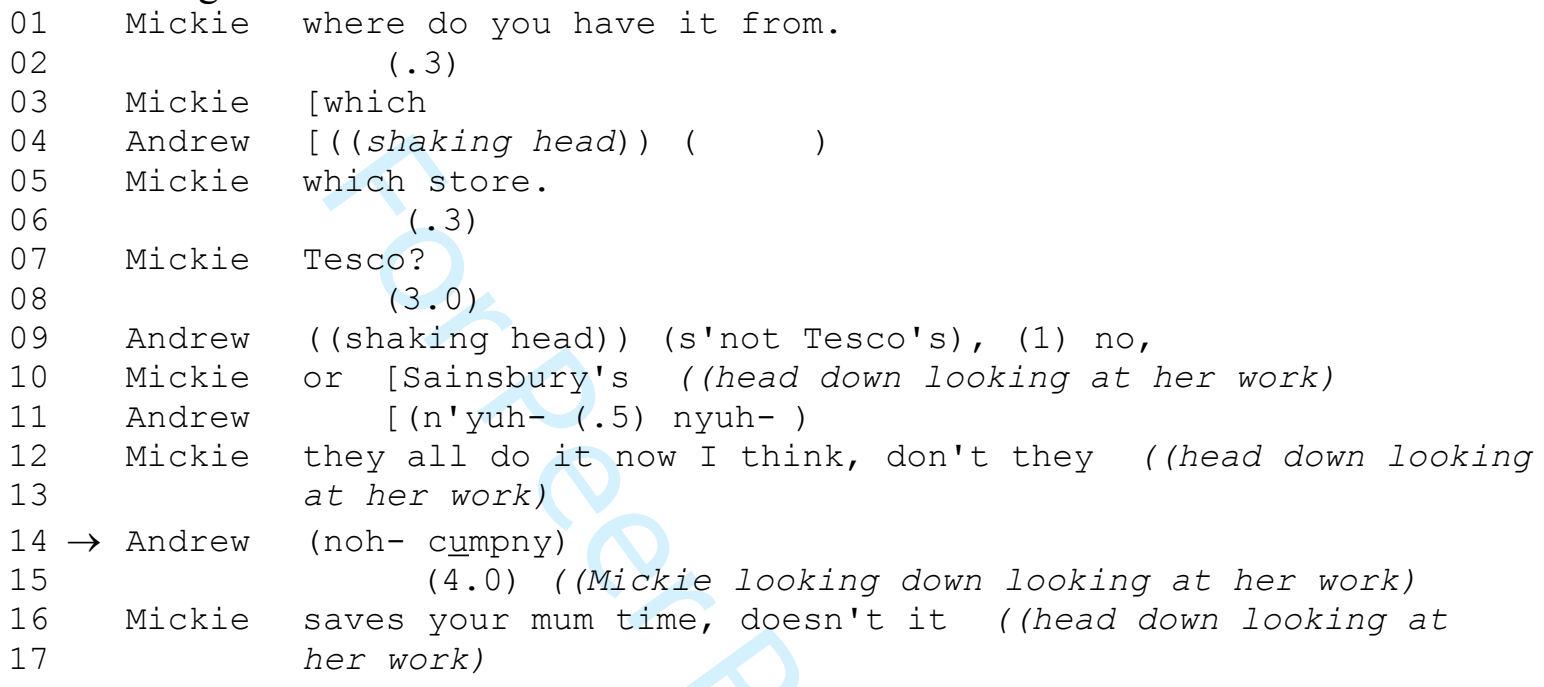

It is perhaps clearer on the video, but Andrew at lines 4, 9, 11 and 14 is trying to formulate a reply to Mickie's enquiry. At 14 he essays what might be a reference to a "company", which might be a relevant answer; but again the physical activity allows the service-provider to concentrate on the work at the expense of orienting to what he says.

Another environment which affords the interlocutor passing over the service-user's deficient response is instruction, especially by means of test-questions - this was a pervasive feature of interactions in all the venues we recorded in, perhaps especially in the end-of-day group discussions at GardenSpace, from where the next example is taken.

Example 6 GardenSpace data 2011-12

00157-quicktime 07.00

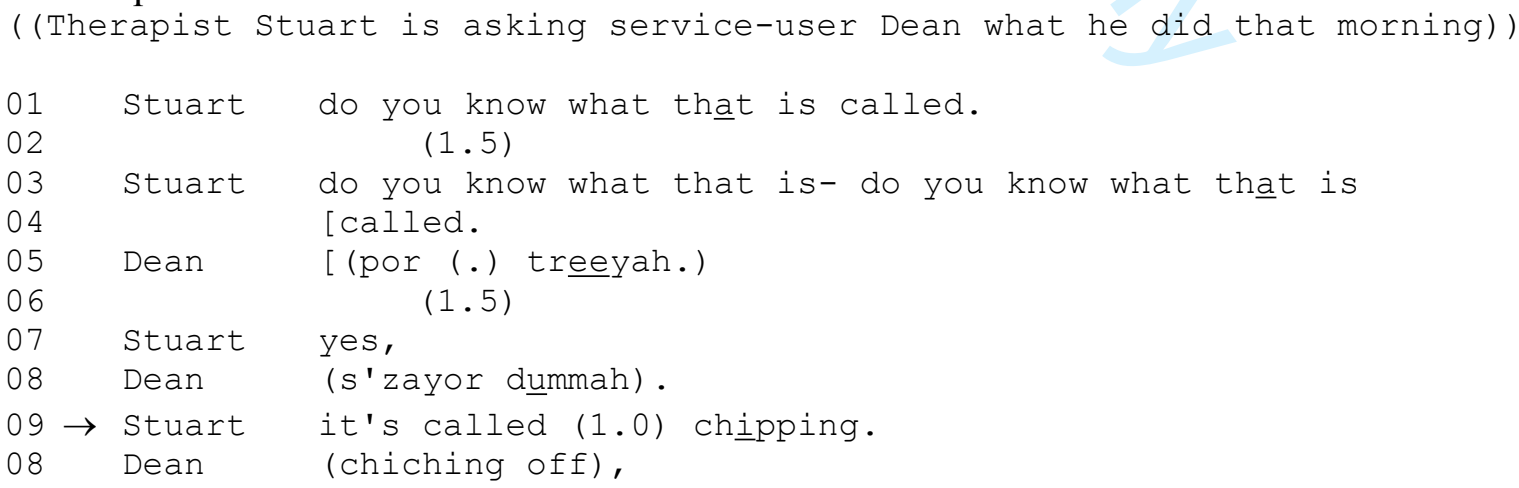

In this typical exchange, the therapist asks the service-user to specify the kind of work he was doing, and gets a reply which is difficult to decipher. It is, however, a test question, and the therapist knows the answer (such practices are common in educational settings - see Koole 
2015). Rather than require Dean to repair either of his attempts (lines 5 and 8), Stuart simply produces the answer as a declarative, without reference to the repairable utterance that Dean had offered.

\section{$\underline{\text { Respond only minimally to a repairable utterance }}$}

When the person with intellectual impairment's utterance is to be met with at least some next turn from the interlocutor, a variety of what Barnes and Ferguson call "receipting responses" are available, all avoiding the unintelligibility of what has been said, while committing themselves to no substantive topical content. We have already seen, in Example 3 above, Mickie receipting Douglas's turn with the general purpose you reckon? (a British idiom which is equivalent to oh yeah?). Here are some more examples.

\section{Example $7 \mathrm{HC} 15$}

01.10

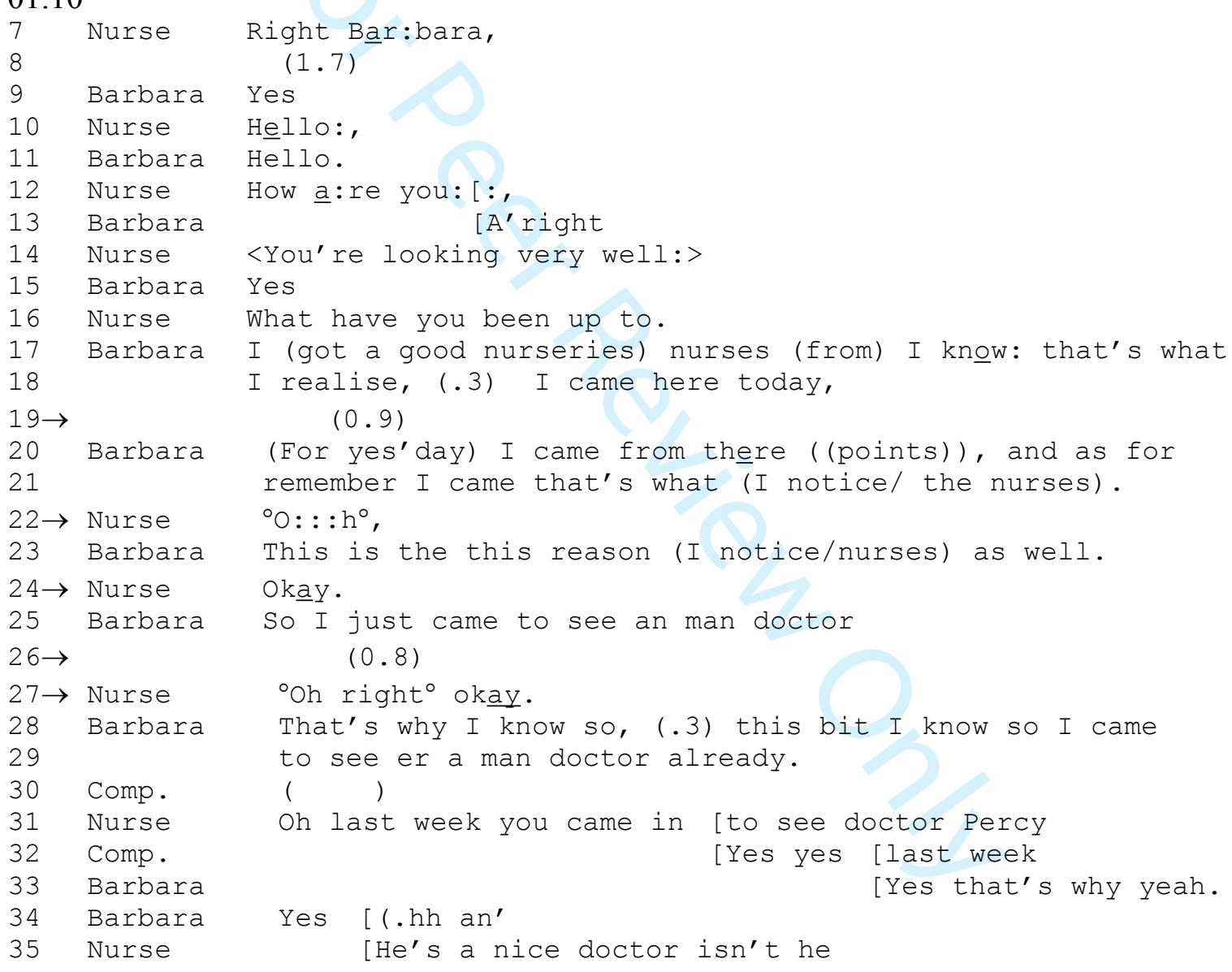

Note that Nurse has asked Barbara "what have you been up to". But Barbara's answers, where decipherable, don't seem to relate to the everyday news that the question conventionally solicits. The nurse passes up a number of opportunities (at the arrowed lines) to issue an OIR, giving instead a variety of unspecific news receipt. And these unspecified news receipts function as continuers in so far as the occupy the next slot allowing the turn to revert to the first speaker. The unintelligibility is just accepted, intelligibility and intersubjectivity are sacrificed to progressivity at the purely structural level, which affords the possibility that intelligibility might emerge at some later point, as it does at $28-29$, which the nurse subsequently takes up. 
In this next case, below, of minimal responses, a community nurse is preparing service-user Barry for an upcoming health-check meeting. Barry has launched an anecdote about an episode from his working life.

Example 8. CTLD4: Barry and the bottle 13.50

((Barry is telling a story about someone giving him a bottled drink with an unusual taste. He uses a good deal of gesture and facial expression, and the gist of it seems to be that the stuff tasted nasty, but some of what he says is not strictly intelligible lexically) )

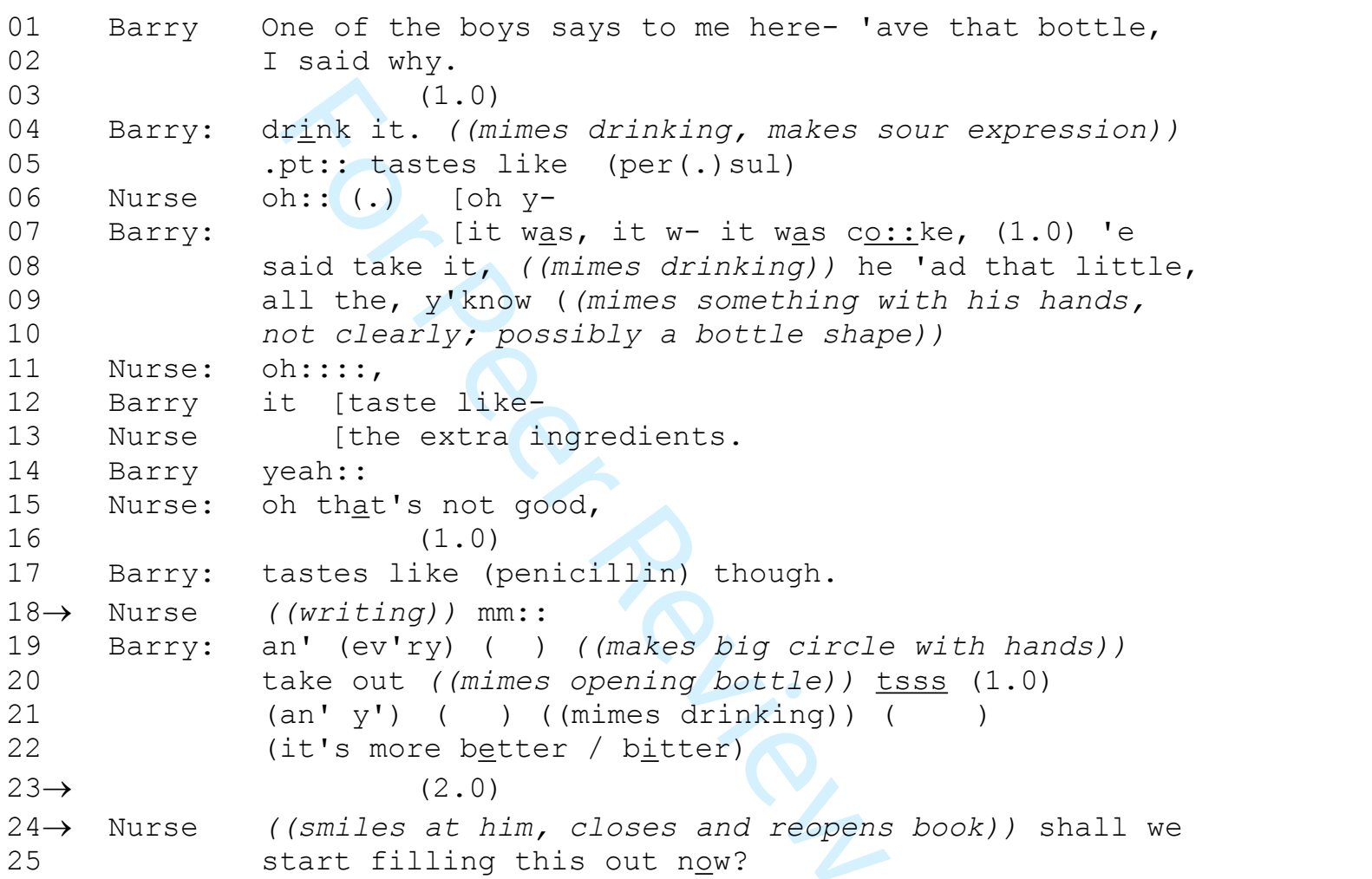

The beginning of Barry's story (lines 1-5) is clear enough; but at lines 8-10 it becomes obscure as his gestures fail to convey any specific meaning. The nurse offers a candidate understanding at 13 (we shall return to this below). The matter seems to be resolved and the punchline established (the drink tastes like (penicillin)) and although "penicillin" seems an odd choice for a taste comparison, the nurse lets it go with only an $\mathrm{mm}$ receipt. Barry launches what seems to be a post-completion reprise in lines 19-22, but once again it is difficult to understand; the nurse passes up the opportunity to receipt what he says (still less initiate its repair) and instead moves to next business.

\section{Embedded correction.}

The examples in the sections above have shown the staff member at pains to either avoid requiring a turn from the service user, or, by responding minimally or not at all, to avoid issuing a repair initiator where possible. However, staff on occasion do indeed orient to difficulties in the service user's talk; but the repair need not be overt. Here are examples of embedded corrections (Jefferson, 1987), where the difficulty is ironed out by stealth. 


\section{Example 9}

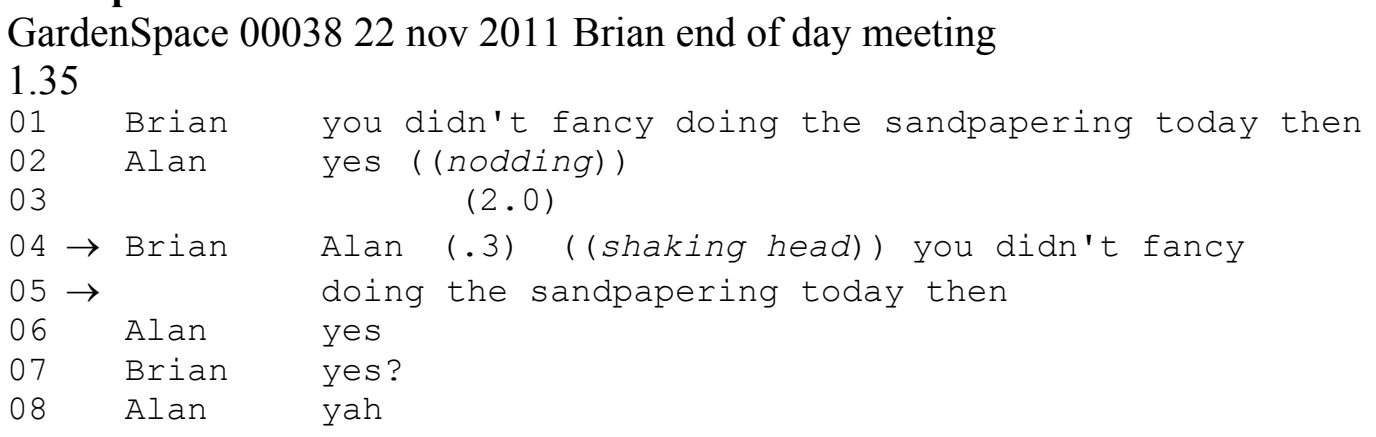

Staff member Brian asks service-user Alan a negative-polarity question which normally projects a "no" in agreement ${ }^{2}$. This is a comparatively complex pragmatic requirement (see Koshik, 2002), and Alan fails to decode it, giving instead an affirmative response. This is met by a silence from Brian, perhaps in order for Alan to self-repair, but when he does not do so, Brian reissues the question, but this time with a helpful headshake to point Alan in the right direction. Issuing the question as if for the first time is effectively a repair, or perhaps more strongly a correction, of an implied failed action. It nevertheless fails.

A more resolute embedded repair is shown in the next example, where the doctor simply recasts what the patient says in more intelligible form.

\section{Example 10.}

$\mathrm{HC} 4$

03.50

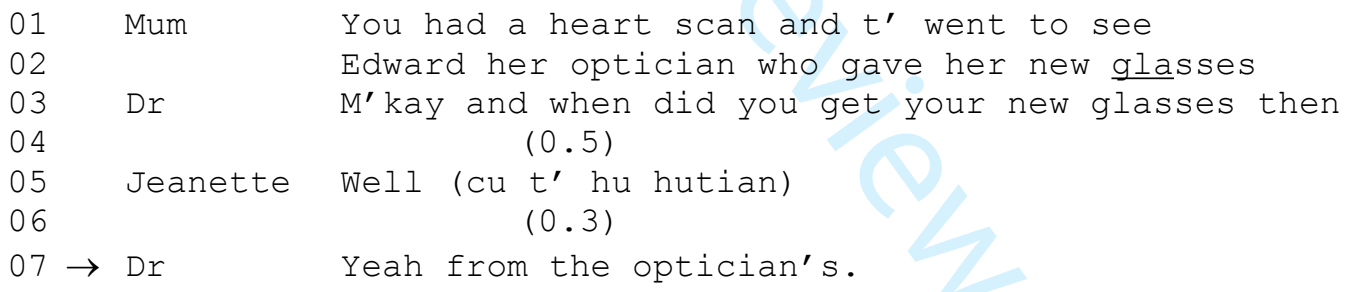

Service-user Jeanette's disfluent utterance at line 5 is repaired by the doctor as if in a restatement (prefaced by the agreeing yeah), rather than queried. The benefit of this form of embedded repair (as opposed to the more tentative one used by Brian, above), is that as a confirmatory acknowledgement itself, it projects no further turn from the repaired speaker Jeanette is not obliged to reconfirm (what is cast as) her own statement.

\section{$\underline{\text { Other-initiated repair }}$}

So far we have seen interlocutors avoiding having to repair the talk of people with intellectual disabilities, or receipting their repairable talk minimally or not at all, or repairing it in disguised ways. But of course interlocutors do use explicit other-initiated repair, and they do so in much the same mix as any conversationalists. It might be worth revisiting the way that Kitzinger (2012) puts OIRs, following Schegloff et al (1977), on a cline "from 'weaker' (i.e. showing least grasp of trouble source turn) to 'stronger' (i.e. claiming a virtually adequate understanding, subject to confirmation" (Kitzinger, 2012, p 249).

\footnotetext{
2 It would certanly be possible to deliver the expected agreement by a "yes", but that would
} usually require some expansion (eg yeah, didn't fancy it), which Brian does not provide. 
The notion of a weaker or stronger grasp on the to-be-repaired meaning is sensible as an account from the perspective of the repair-initiator. But may not suit us here; it might be more profitable, or at least more in tune with the line we've taken so far, to keep in mind the asymmetry between repair initiator and repairee, and lay out the range along the spectrum of the demands it makes on the person with disabilities. In that case, an open class repair initiator (like what? or sorry?) is at the lowest end of the help it gives, while the candidate understanding, which merely requires assent, makes the least demands and offers the easiest path to progression. That seems a more appropriate characterisation in these data, as it also allows us to include repair being used for other-correction (which features in Kendrick's 2015 account of OIRs, but not in Kitzinger's). We will give examples of each sort, starting with helpful candidate understandings, and working along to the challenging corrections.

a) candidate understandings

Here the staff member proposes a reading of what the service-user has said. We have already seen, in passing, an example in the case above of Barry. He is recounting his experience of a nasty drink:

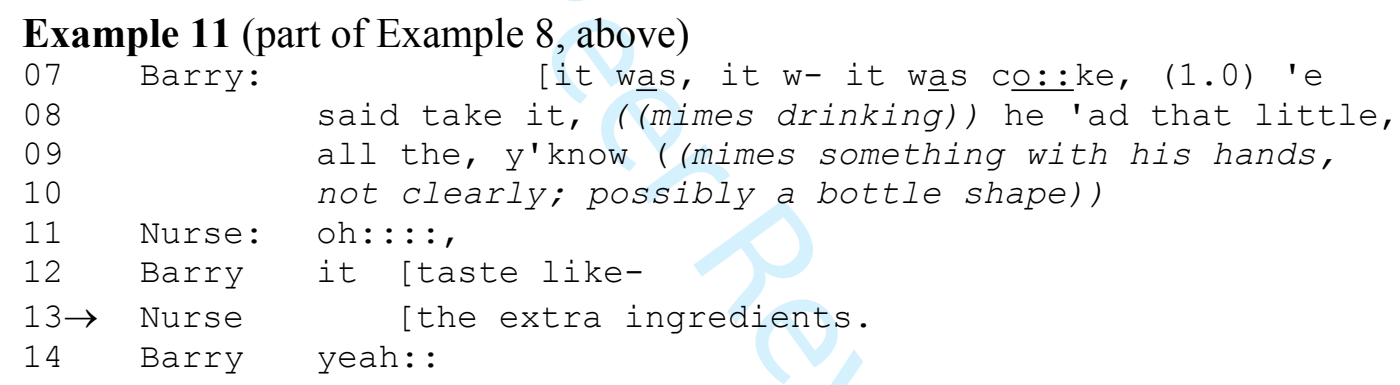

The nurse offers a formulation of his difficult-to-understand uterance and mime at lines 7-10 as being a matter of identifying extra ingredients as the cause of the nasty taste. Here is an other example of the same kind.

Example 12. Foxwood.

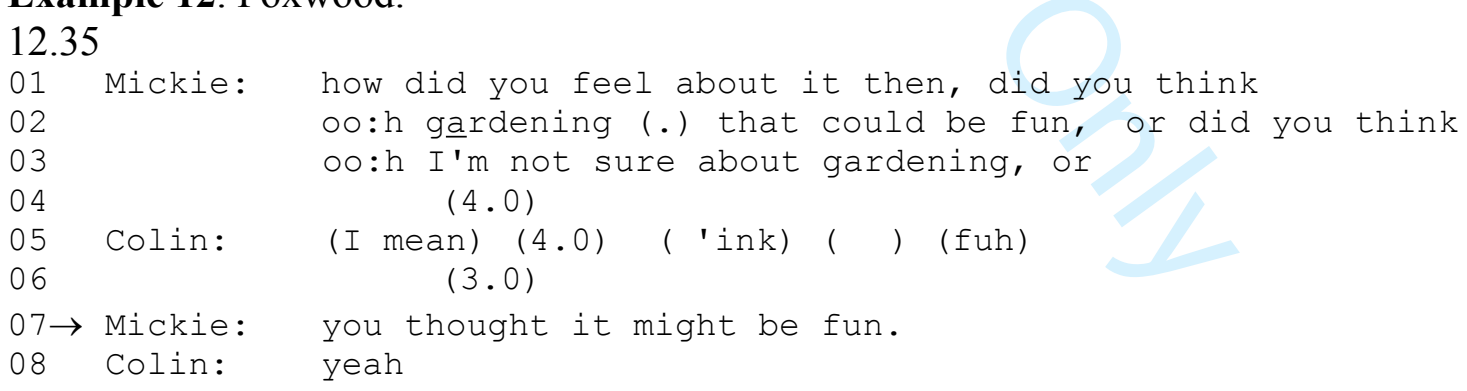

The thing to note about such candidate understandings - apart from the obvious point that they construct a meaningful, appropriately-formatted and sensible utterance out of comparatively thin material - is that they are posed as declaratives; they require nothing further from the recipient than confirmation or assent.

b) category specific repair initiators

Here the OIR doesn't supply an alternative to the offending item, but it does identify the information (or class of information) that is missing or otherwise deficient.

\section{Example 13}


$\mathrm{HC} 7$

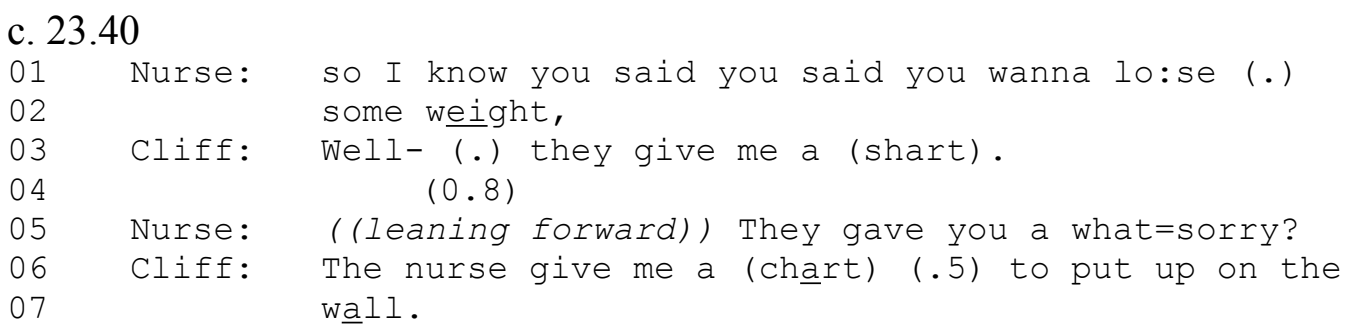

Here the staff member has at least identified the element of the service-user's turn that requires fixing: she repeats the stem of the sentence to indicate exactly which word still remains to be adequately specified. The service user can use that scaffolding to provide the appropriate response.

c) Repeats

Repeat OIRs are less complete than candidate understandings, and less informative about what is wanted than category-specific repair initiators, but at least they identify what it is about the utterance that requires fixing. There were very few of these in the data, and none that called for 'mere' repair; as Kendrick points out, "a speaker may use a practice that formally resembles an OIR, but the action that the practice analyzably delivers is not an other-initiation of repair", and that seems to be especially true of the (few) uses of repeats in these data. Here is an example:

Example 14 Comber Hall Way VC11 c. 09.40

Service-user Dominic is recounting a story to staff-member Peter

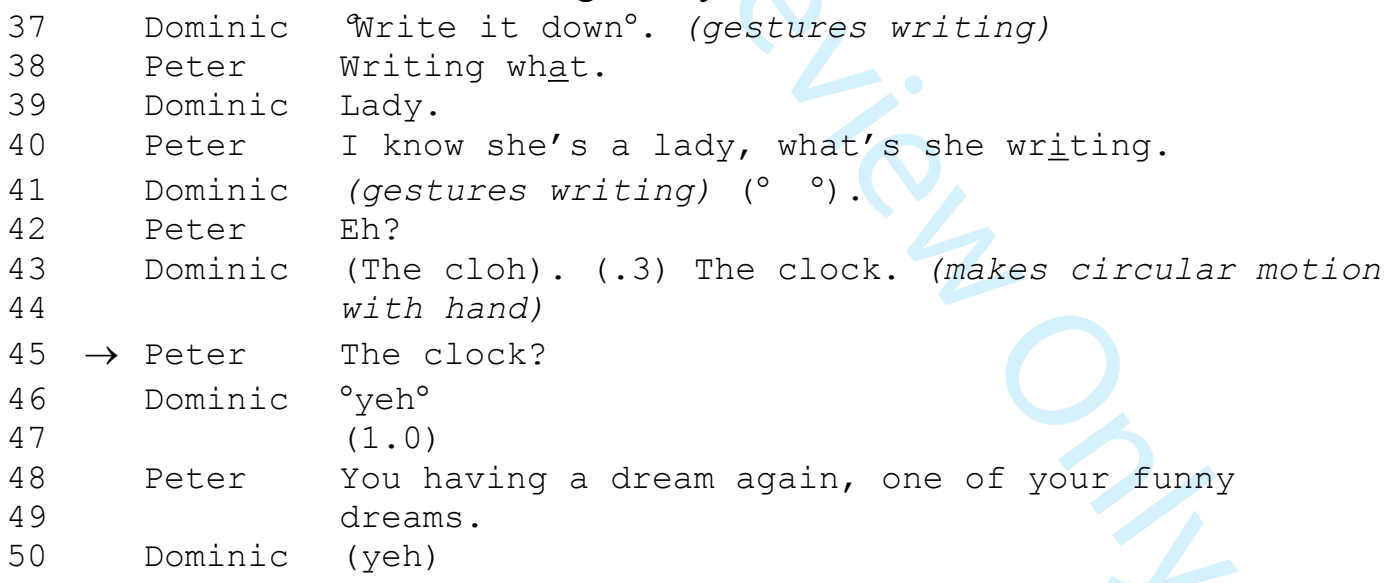

Peter's repeat, with rising inflection, of Dominic's spoken and mimed turn at 43 does indeed invite a repair, but as the tape plays on, it becomes clear at line 48 that Peter is treating it as more than as it were 'merely' repairable; he treats is as being hard to square with the rest of the narrative so far, warranting him to project an end of the sequence by treating at as (no more than) one of Dominic's funny dreams.

d) open-class repair initiators

These are straightforward uses of conventional indicators that something (unspecified) is amiss in wat the previous speaker has said. Two examples:

\section{Example 15}

Charnwood: Cutting back plants 13.50 
((the sound of an emergency vehicle has just gone by out of shot, possibly an ambulance; Steven has briefly imitated its siren))

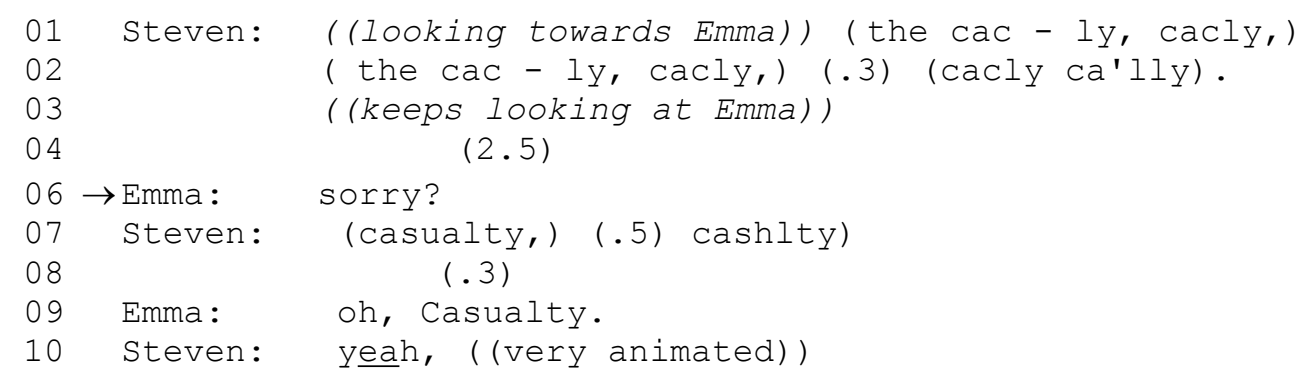

\section{Example 16}

GardenSpace

00062-quicktime 06.20

((Jess has invited Alan to write something in his Christmas card, and after he declines various possibilities, the sequence runs dry.))

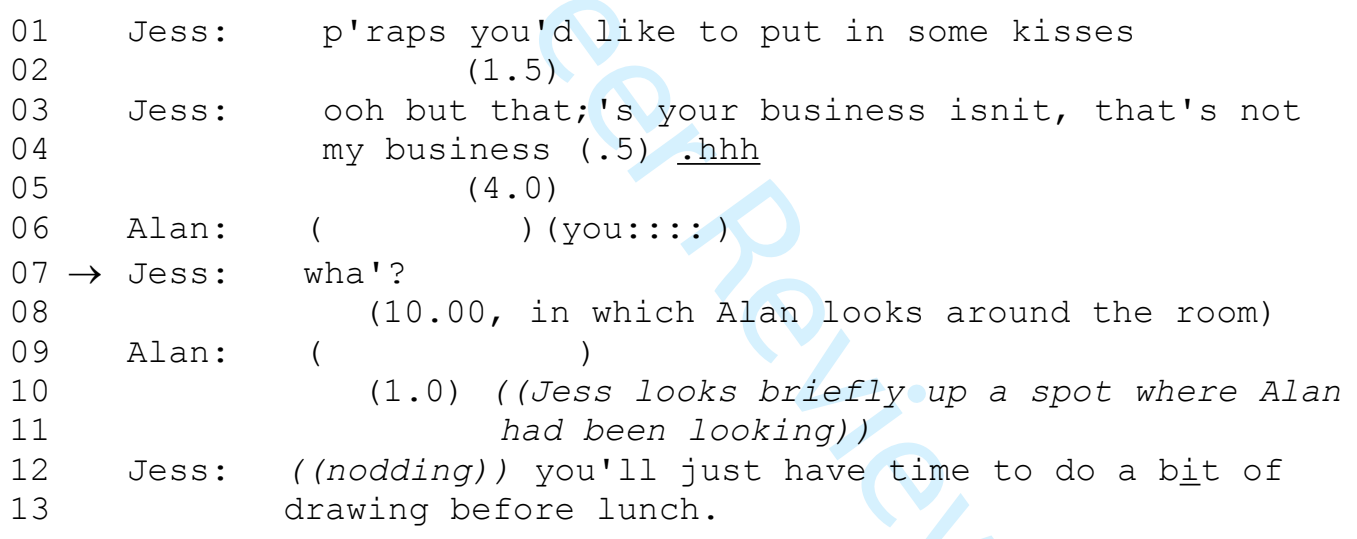

In both cases, the staff member has only alerted the service-user that something is amiss with what they've said, without identifying exactly what it is that wants specifying. The default would be that the problem is merely auditory, and that succeeds in Example 15, but not in 16, where staff member Jess's wha'? elicits no repair from Alan.

\section{f) Corrections}

Here we have moved away from as it were no-fault repair, or at least repair initiators which are consistent with a purely mechanical problem (for example, in hearing what was said). The repair initiators here explicitly cast what the speaker has said as wrong or otherwise inadequate in the circumstances.

Example 17 - a mitigated correction

GardenSpace

00148 quicktime 03.50

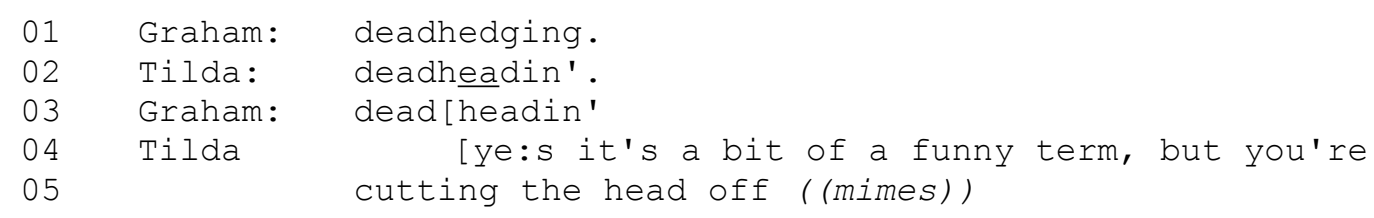


Example 18 - another mitigated correction

GardenSpace

00044-quicktime 07.00

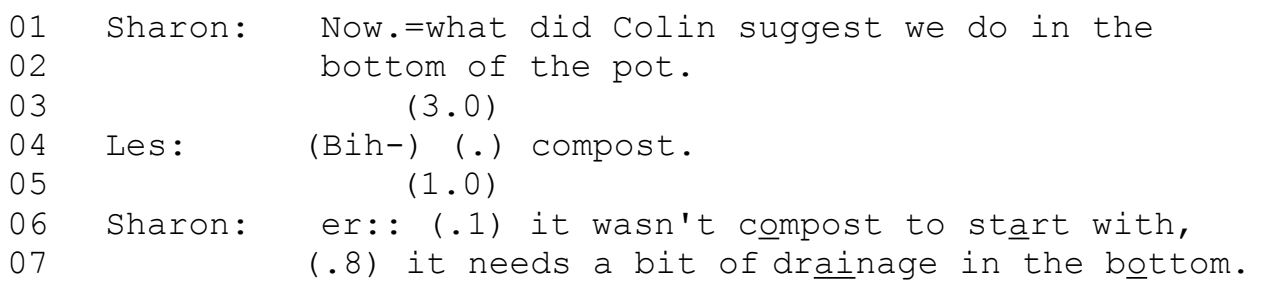

Corrections are dangerous; they claim a greater knowledge of what the speaker is trying to say, or ability to say it, than the speaker has themselves. The corrector's rights in the matter seem to be, in the examples above, technical, and are in any case mitigated with an account. They meet no resistance. Compare that with what happens in this last example, where a mother corrects her adult son:

Example 19 - a bald correction sequence

HC5 $(\mathrm{SU}=$ Luke, companion $=$ Catherine, mother $)$

c. 12.30
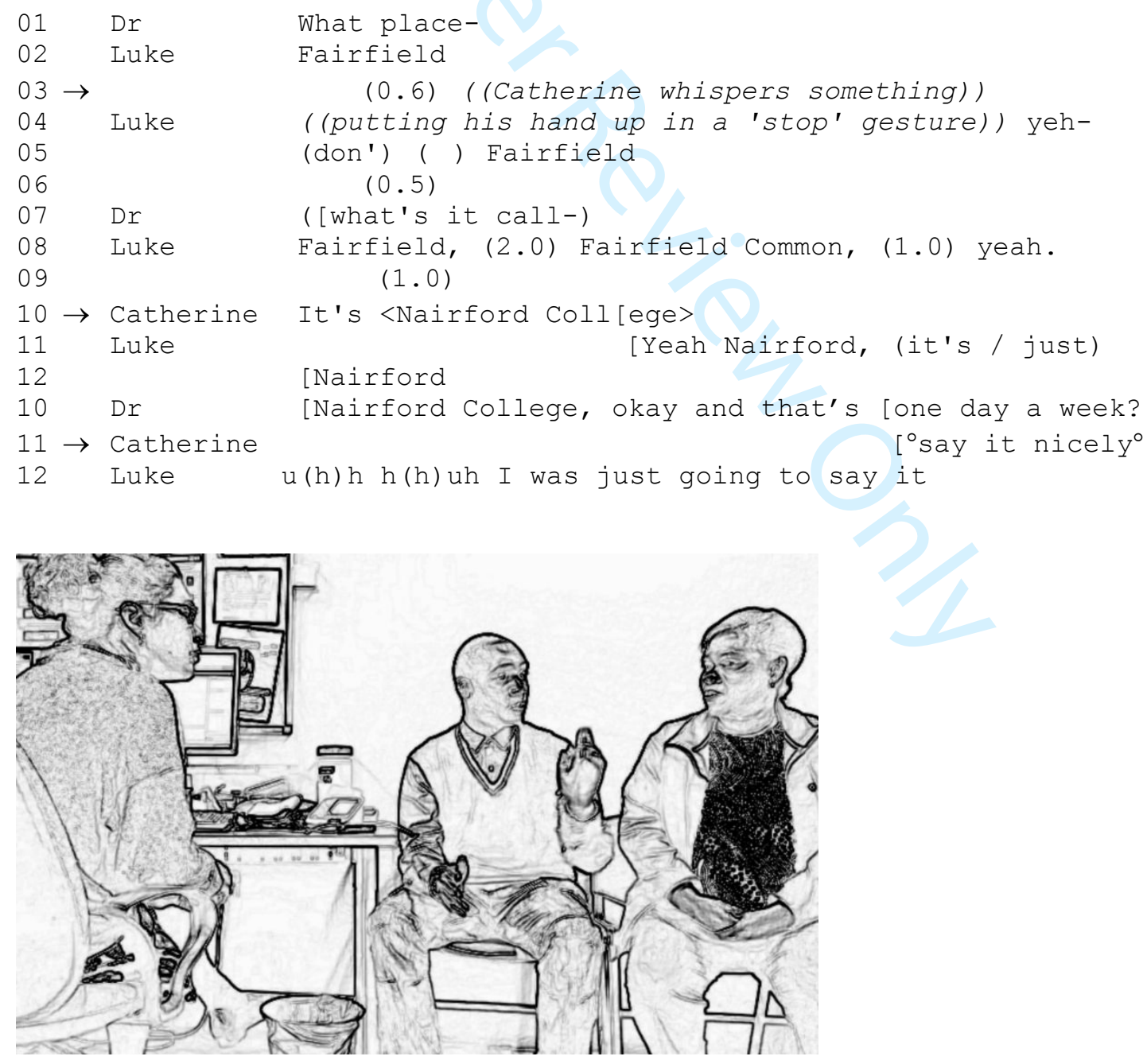

Figure 4: Luke puts his hand up as Catherine whispers to him (line 4) 
Service-user Luke's Fairfield in line 2 seems prompts Catherine to issue something privately, but Luke meets it with a distinct "stop" gesture (line 4) and what might be a don't in line 5. At 10 Catherine issues a bald correction it's Nairford College, enunciated deliberately, and with a further injunction to say it nicely (line 11). The sequence is a great deal more turbulent than the exchanges in Examples 17 and 18 above.

\section{$\underline{\text { Discussion }}$}

Although we have set out the findings in a list that goes from avoidance of any need for repair (by not requiring the other person to speak) to the other extreme of explicitly calling out a mistake and correcting it, we don't mean to say that service-provider staff have a live gradient in their minds as they communicate with service users. Still less do we think that they work successively through the options, first trying to avoid getting the user to talk, and only as a last resort issuing an explicit correction. There is no evidence to support such a claim, and in any case, it seems a very implausible picture of the daily round of the serviceprovider's duties; they move from task to task, and respond to the contingencies of the situation. But it is plausible as a conceptual scale along which to range the options, consciously chosen or not. As for the motivation to move up and down the range, that is outside the scope of an analysis like this, but some speculation is probably permissible.

We have hinted at a number of motivations that might be factors in the movement up and down the scale: regard for the recipient's "face", in terms of politeness theory; very local interactional concerns such as moves-to-closure; the tension inherent in epistemic asymmetry.... Perhaps the most satisfying candidate is some amalgam of the serviceprovider's institutional mandate to get the local job done, while respecting their organisation's more global aspiration to support the service-users through their difficulties (these are, after all, all welfare-oriented organisations, from the health service to a horticulture therapy charity). To some degree these are countervailing motivations: if the local job is to get a wheelbarrow shifted, or find out if the patient smokes, at least some of what the service-user says might be superfluous, or ignorable, or - in terms of the immediate job requirements - not worth repairing. On the other hand, if the service-user has essayed some sort of contribution to the interaction, a mandate to support them would commit the service-provider to try to figure out that they mean, and that would at least sometimes entail initiating a repair. Which side the staff member falls on at any one time will, in the end, be a function of unknowable numbers of factors.

In terms of the net effects of these practices for how people with intellectual disabilities communicate, sensitive practices of OIR that encourage and support people to build on initially unclear utterances, or to develop responses that are not pre-determined, are more respectful of their contributions, allow SUs to have more influence over the conversation, and are presumably beneficial to the development of the person's confidence and social skills in the long term. For the interlocutors, use of OIRs can be a useful way of them developing more in-depth knowledge about how the person communicates and what sort of 'content' they might be able to contribute to particular topics. The picture is complicated somewhat in that people with intellectual disabilities vary widely in terms of their cognitive and communicative abilities, and some of the OIR practices which require no or minimal response might be due to the interlocutor's inability to understand that person's verbal communication in past encounters, or their knowledge that the SU is unable to respond to requests for clarification. In these cases, such OIRs function to avoid further frustrating turns 
which might, in the long term, discourage the person from trying to communicate. The danger, of course, is that interlocutors fail to develop knowledge of the SU and their communicative styles and abilities because they are afraid of causing frustration. 


\section{$\underline{\text { References }}$}

Barnes, S., \& Ferguson, A. (2015). Conversation partner responses to problematic talk produced by people with aphasia: Some alternatives to initiating, completing, or pursuing repair. Aphasiology, 29(3), 315-336.

Drew, P. (1997). 'Open'class repair initiators in response to sequential sources of troubles in conversation. Journal of pragmatics, 28(1), 69-101.

Goodwin, C. (1995). Co-constructing meaning in conversations with an aphasic man. Research on Language and Social Interaction, 28, 233-260.

Goodwin, C. (Ed.). (2003a). Conversation and Brain Damage. Cambridge: Cambridge University Press.

Heritage, J., \& Raymond, G. (2005). The terms of agreement: Indexing epistemic authority and subordination in talk-in-interaction. Social Psychology Quarterly, 68(1), 15-38.

Jefferson, G (1987) On exposed and embedded correction in conversion. G. Button, JR Lee (Eds.), Talk and social organisation. Clevedon: Multilingual Matters, pp. 86-100

Kendrick, K. H. (2015). Other-initiated repair in English. Open Linguistics, 1(1).

Kitzinger, C. (2012). Repair. The handbook of conversation analysis, 229-256.

Koole, T. (2015). Classroom interaction. International Encyclopedia of Language and Social Interaction. Wiley-Blackwell.

Koshik, I. (2002). A conversation analytic study of yes/no questions which convey reversed polarity assertions. Journal of Pragmatics, 34(12), 1851-1877.

Laakso, M. (2003). Collaborative construction of repair in aphasic conversation: An interactive view on the extended speaking turns of persons with Wernicke's aphasia. In C. Goodwin (Ed.),Conversation and brain damage (pp. 163-188). New York, NY: Oxford University Press

Lerner, G. H. (1991). On the syntax of sentences-in-progress. Language in society, 20(3), 441-458.

Mandelbaum, J. (1991). Conversational non-cooperation: An exploration of disattended complaints. Research on Language \& Social Interaction, 25(1-4), 97-138.

Perkins, L. (1995). Applying conversation analysis to aphasia: Clinical implications and analytic issues. European Journal of Disorders of Communication, 30, 372-383.

Perkins, L. (2003). Negotiating repair in aphasic conversation. In C. Goodwin (Ed.), Conversation and brain damage (pp. 147-162). New York, NY: Oxford University Press. 
Radford, J., Ireson, J., \& Mahon, M. (2012). The organization of repair in SSLD classroom discourse: how to expose the trouble-source. Journal of Interactional Research in Communication Disorders, 3(2), 171.

Sacks, H., Schegloff, E. A., \& Jefferson, G. (1978). A simplest systematics for the organization of turn taking for conversation. In Studies in the organization of conversational interaction (pp. 7-55).

Schegloff, E. A., Jefferson, G., \& Sacks, H. (1977). The preference for self-correction in the organization of repair in conversation. Language, 53(2), 361-382.

Stevanovic, M., \& Peräkylä, A. (2012). Deontic authority in interaction: The right to announce, propose, and decide. Research on Language \& Social Interaction, 45(3), 297-321.

Stivers, T., \& Rossano, F. (2010). Mobilizing response. Research on Language and social interaction, 43(1), 3-31.

Wilkinson, R. (1995). Doing 'being ordinary': Aphasia as a problem of interaction. Work in Progress, 5, 134-150.

Wilkinson, R. (1999). Sequentiality as a problem and resource for intersubjectivity in aphasic conversation: analysis and implications for therapy. Aphasiology, 13(4-5), 327-343. 